\title{
LV-PP-1-5
}

\section{Accuracy of new formula for standard liver volume using L3 skeletal muscle index}

\author{
Shin HWANG*
}

Department of Surgery, Asan Medical Center, University of Ulsan College of Medicine, Seoul, Korea

Introduction: Formula-derived standard liver volume (SLV) has been clinically used for living donor liver transplantation and hepatic resection. The majority of currently available SLV formulae are based on body surface are (BSA), but they often show wide range of error. Skeletal muscle index measured at the third lumbar vertebra level (L3SMI) appears to reflect the lean body mass.

Methods: We intended to establish a new SLV formula using L3SMI. The development cohort was 500 hundred living liver donors.

Results: The study cohort included 250 male and 250 female donors. The age was $25.9 \pm 8.2$ years. The mean values were BSA $1.70 \pm$ $0.1 \mathrm{~m}^{2}$, L3SMI $45.4 \pm 9.0 \mathrm{~cm}^{2} / \mathrm{m}^{2}$, and body mass index $21.8 \pm 2.5 \mathrm{~kg} / \mathrm{m}^{2}$. BSA-based SLV formula was “SLV $(\mathrm{mL})=969.8 \times$ BSA $\left(\mathrm{m}^{2}\right)-$ 456.3", which was previously developed. L3SMI-based SLV formula was "SLV $(\mathrm{mL})=23.3 \times \mathrm{L} 3 \mathrm{SMI}\left(\mathrm{cm}^{2} / \mathrm{m}^{2}\right)+133$ ” $($ Spearman $\mathrm{rho}=$ $0.71[p<0.001])$. The BSA-based formula showed Spearman rho $=0.69(p<0.001)$. L3SMI-based SLV formulae were "SLV (mL) $=24.0$ $\times \operatorname{L3SMI}\left(\mathrm{cm}^{2} / \mathrm{m}^{2}\right)+80$ " ( $\left.\mathrm{rho}=0.69[p<0.001]\right)$ for males and "SLV $(\mathrm{mL})=24.0 \times \mathrm{L} 3 \mathrm{SMI}\left(\mathrm{cm}^{2} / \mathrm{m}^{2}\right)+80$ " (rho $=0.26[p=0.15]$ for females. BSA-based formula showed rho $=0.65(p<0.001)$ for males and rho $=0.43(p=0.027)$.

Conclusions: L3SMI-based SLV formula resulted in higher accuracy than BSA-based formula in male individuals, but paradoxically showed lower accuracy in female individuals, probably due to different distribution of L3SMI values. Further high-volume validation studies are necessary to use L3SMI-based SLV formulae in practice. 